\title{
Slope-Area Computation Program Graphical User Interface 1.0-A Preprocessing and Postprocessing Tool for Estimating Peak Flood Discharge Using the Slope-Area Method
}

\section{Introduction}

The slope-area method is a technique for estimating the peak discharge of a flood after the water has receded (Dalrymple and Benson, 1967). This type of discharge estimate is called an "indirect measurement" because it relies on evidence left behind by the flood, such as high-water marks (HWMs) on trees or buildings. These indicators of flood stage are combined with measurements of the cross-sectional geometry of the stream, estimates of channel roughness, and a mathematical model that balances the total energy of the flow between cross sections. This is in contrast to a "direct" measurement of discharge during the flood where cross-sectional area is measured and a current meter or acoustic equipment is used to measure the water velocity. When a direct discharge measurement cannot be made at a gage during high flows because of logistics or safety reasons, an indirect measurement of a peak discharge is useful for defining the high-flow section of the stage-discharge relation (rating curve) at the stream gage, resulting in more accurate computation of high flows.

The Slope-Area Computation program (SAC; Fulford, 1994) is an implementation of the slope-area method that computes a peak-discharge estimate from inputs of water-surface slope (from surveyed HWMs), channel geometry, and estimated channel roughness. SAC is a command line program written in Fortran that reads input data from a formatted text file and prints results to another formatted text file. Preparing the input file can be time-consuming and prone to errors. This document describes the SAC graphical user interface (GUI), a crossplatform "wrapper" application that prepares the SAC input file, executes the program, and helps the user interpret the output. The SAC GUI is an update and enhancement of the slope-area method (SAM; Hortness, 2004; Berenbrock, 1996), an earlier spreadsheet tool used to aid field personnel in the completion of a slope-area measurement. The SAC GUI reads survey data, develops a plan-view plot, water-surface profile, cross-section plots, and develops the SAC input file. The SAC GUI also develops HEC-2 files that can be imported into HEC-RAS.

\section{Slope-Area Computation Program Graphical User Interface Description}

The SAC GUI is a menu-driven application that reproduces and extends the functionality of SAM. The application is organized around four main menus; File, Edit, View, and SAC. The File menu is similar to the File menu in most modern applications, providing options to launch the New Indirect Wizard (fig. 1), open an existing project file, save changes to a project (the user is encouraged to use this option often), change the project's file name, or quit the application. The File menu also contains options to (1) export plots as 300-dpi portable network graphic (PNG) files, (2) export a HEC-2 formatted file, (3) export cross-section and high-water-mark elevation and stationing, and (4) lock or unlock a project.

The Edit menu provides direct access to the edit screens for the project data. These screens are similar to or identical to those used in the New Indirect Wizard.

The View menu provides access to the plots and the underlying data. Once a plot is loaded into the main window of the application, it behaves in a manner similar to the New Indirect Wizard. For example, the user can edit the channel centerline on the plan-view plot or adjust the water-surface profile on the high-water-mark plot. Plots can also be customized. The user can change the plot symbols, colors, title, axes labels, and other properties by right clicking on a plot to bring up a menu of options. This menu also includes options to save the plot as a 300-dpi PNG file or as an editable vector graphic. The user can also edit the original survey data, but should keep in mind that when any of the raw survey data change, the application must regenerate all plots and, consequently, any plot customizations will be lost.

The SAC menu is used to generate the SAC input files and execute the SAC Fortran program. The Run SAC command opens a window in which the user specifies the names and locations of the SAC input and output files and optional remarks that appear in the SAC output file. When the user executes the SAC program, status messages from SAC are displayed in a window, and if SAC executes successfully, the GUI displays the standard text output from SAC and creates a graphical summary of the SAC output as an energy-profile plot accessible from the View menu. Figure 2 shows the SAC output summarized on the energy-profile plot.

\section{Data Entry and Reach Characterization}

The core of the SAC GUI is the New Indirect Wizard, which guides the user through the process of preparing the data needed to make a slope-area discharge estimate (fig. 1). The 
New Indirect Wizard includes the Project Info screen (fig. 1A), which provides an opportunity for entry of station and reach location and other data relative to the specific slope-area measurement. The required input data include the $x-y-z$ coordinates (expressed as easting, northing, and elevation, in units of feet or meters) of HWMs and cross-section points surveyed in the field (fig. 1B). Azimuth-distance surveys must be converted to $x-y-z$ coordinates prior to using the SAC GUI. The input file must include columns of sequence number, easting, northing, elevation, and a point identifier. An optional remarks column is also supported. The New Indirect Wizard imports tab, comma, or space-delimited ASCII text files, such as those generated by a total station or Global Positioning System (GPS) unit. The columns in the input file can be in any order. The input file requirements are listed in table 1 and table 2 . The point identifier consists of up to three fields delimited by dashes ("-"). The first field is a two- or three-letter code that identifies the type of point. Supported identifier code types are listed in table 2. In the case of a cross section, a unique identification number assigned to that cross section is also given as part of the type assignment. For example, cross section number 3 would begin with "X3-". The second field is the point number. Point numbers represent ongoing benchmark and reference mark numbers established at the gage, surveying or turning-point numbers assigned during the field survey, consecutive ground points along each cross section, or HWM numbers along each bank. The third field is an optional code used to denote the quality of each HWM. Supported quality codes are listed in table 2 .
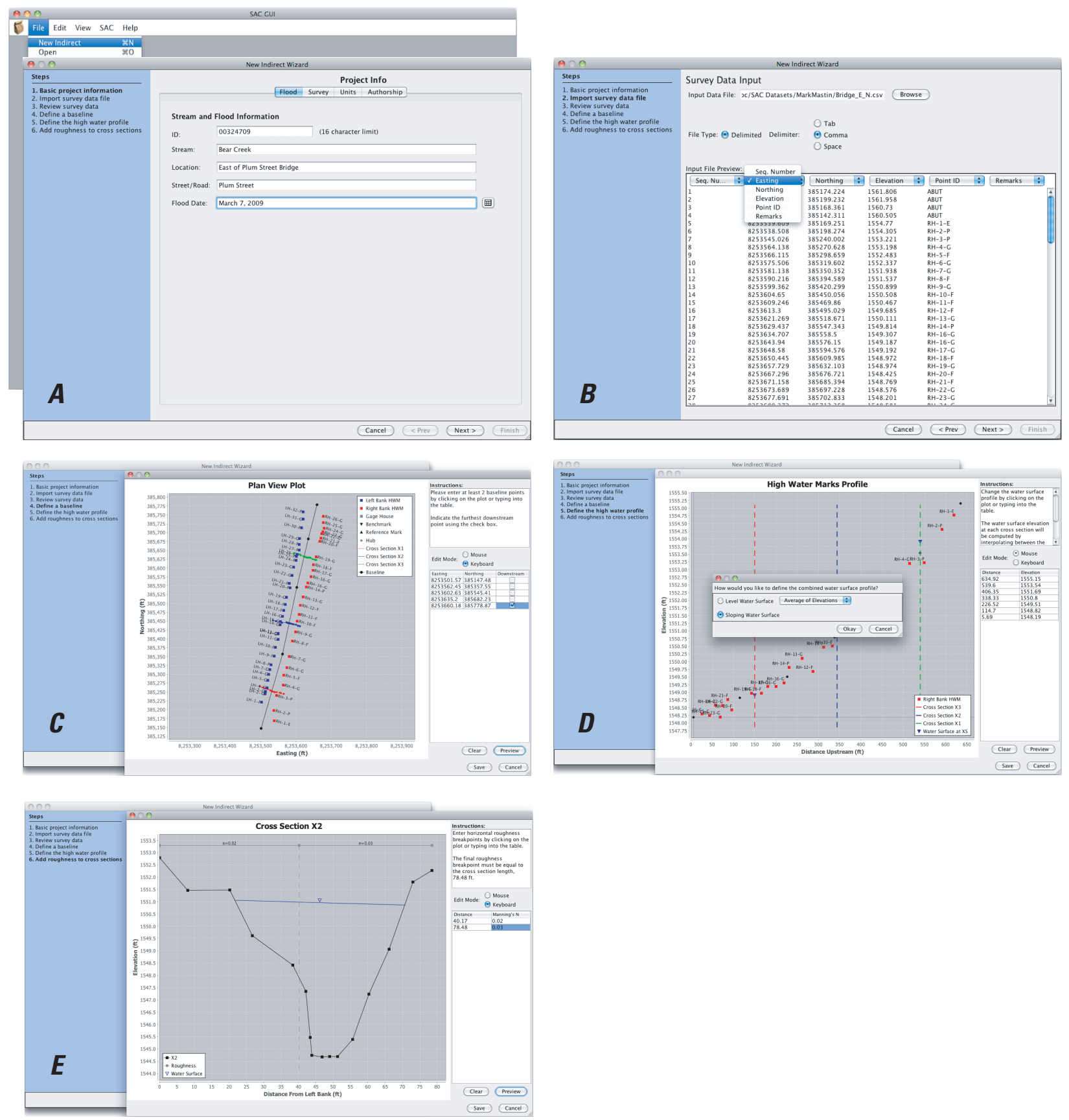

Figure 1. Screen shots of the New Indirect Wizard showing selected steps in the preparation of the Slope-Area Computation program input data $[(A)$ Project Info screen, $(B)$ Survey Data Input screen, $(C)$ Plan View Plot screen, $(D)$ High Water Marks Profile screen, and (E) Cross Section screen]. 

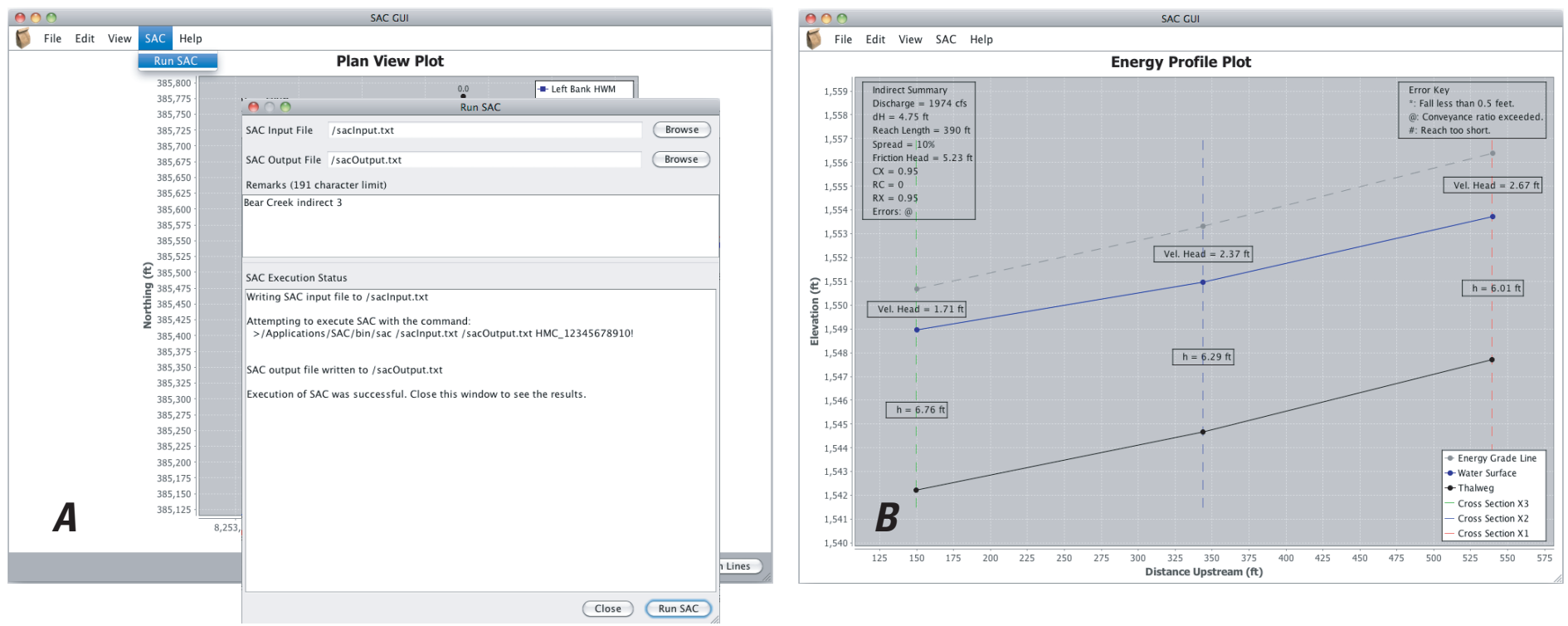

Figure 2. The Graphical User Interface simplifies execution of the Slope-Area Computation program and summarizes the results graphically $[(A)$ Plan View Plot screen and $(B)$ Energy Profile Plot screen].

After importing the survey data, the New Indirect Wizard leads the user through several additional data setup steps. First, the user defines a channel centerline by either clicking on a plan-view plot of the survey data (fig. $1 C$ ) and (or) by typing coordinates into a table. The channel centerline is used to compute the stationing of HWMs and cross sections (fig. 1D). The centerline can be curved and should extend beyond the range of the survey data. The user specifies the flow direction by marking the furthest downstream centerline point. If cross sections have been included in the input file (fig. $1 E$ ), the New Indirect Wizard fits cross-section lines to the cross-section points and includes them in the plan-view plot. The user can override the default cross-section line by clicking on the plot to define a new line. The distance from the left bank of each cross-section point (stationing along a cross section) is computed by projecting each survey point onto the cross-section line.

Next, the user defines the water-surface elevation profile(s) along the reach. The New Indirect Wizard generates three HWM-profile plots: a plot of left-bank HWMs, a plot of rightbank HWMs, and a plot including HWMs of both the left and right banks. The user can define left-bank and right-bank watersurface profiles by clicking on the plots or by typing distances and elevations into a table. If cross sections have not yet been surveyed, the high-water-mark profile plots can be used to decide where they should be located. In this case, the user exits the New Indirect Wizard and restarts the process after cross sections have been surveyed. Otherwise, the New Indirect Wizard proceeds to the next step.

Once the cross-section points have been surveyed and included in the input file, the user can also define a "combined" water-surface profile. SAC uses the elevations defined in the combined profile to establish water-surface elevation at each cross section. A combined profile is created by (1) entering the water-surface elevation at each cross section into a table or (2) letting the program automatically compute an average of the two profiles (interpolated for each cross section). The second option uses the left- and right-bank profiles to define a sloped water surface. In this case, SAC uses the sloped surface to compute the hydraulic properties of each cross section and the average water surface to compute the fall between sections. When the sloping water-surface option is used, the combined profile cannot be edited.

The final step is to specify the channel roughness by entering a Manning's $n$ value for the complete cross section or by dividing each cross section into subareas with differing values of Manning's $n$. Each cross section must include at least one roughness subarea. The subareas are separated by horizontal roughness breakpoints defined by clicking on the cross-section plot and entering the Manning's $n$ value into a table. The user can also adjust the water-surface elevation at a cross section (defined in the previous step) if it looks incorrect when plotted along with the cross section. Any updates to the water-surface elevation made here are reflected in the combined water-surface-profile plot.

Once the user has finished the steps described above using the New Indirect Wizard, the rest of the process, including execution of the SAC program, graphical interpretation of the SAC output, and project file management takes place within the main window of the SAC GUI.

\section{Obtaining and Installing the Slope-Area Computation Program and the Slope-Area Computation Program Graphical User Interface}

The SAC GUI is a runnable Java Archive that interfaces with the SAC command-line Fortran program. The SAC GUI and SAC have been successfully run under Windows and Macintosh operating systems. The SAC GUI, SAC, example datasets, documentation, installation requirements, and an installer can be found at the U.S. Geological Survey SAC/SAC GUI Web page (http://water.usgs.gov/software/SAC/). 
Table 1. Input data file fields.

\begin{tabular}{|c|c|c|c|}
\hline Field & Description & Data type & Required? \\
\hline $\begin{array}{l}\text { Sequence } \\
\text { number }\end{array}$ & & Integer & Yes \\
\hline Easting (x) & $\begin{array}{l}\text { Distance east } \\
\text { of some } \\
\text { datum }\end{array}$ & Number & Yes \\
\hline Northing (y) & $\begin{array}{l}\text { Distance north } \\
\text { of some } \\
\text { datum }\end{array}$ & Number & Yes \\
\hline Elevation (z) & $\begin{array}{l}\text { Height relative } \\
\text { to some } \\
\text { datum }\end{array}$ & Number & Yes \\
\hline Point identifier & $\begin{array}{l}\text { A combination } \\
\text { of characters } \\
\text { and digits } \\
\text { identifying } \\
\text { the point }\end{array}$ & $\begin{array}{l}\text { Alpha-numeric } \\
\text { characters } \\
\text { (see table 2) }\end{array}$ & Yes \\
\hline Remarks & $\begin{array}{l}\text { Comments } \\
\text { about the } \\
\text { point }\end{array}$ & $\begin{array}{l}\text { Up to } 50 \text { alpha- } \\
\text { numeric } \\
\text { characters }\end{array}$ & No \\
\hline
\end{tabular}

\section{References Cited}

Berenbrock, Charles, 1996, A procedure to generate slope-area plots and compute estimated discharge for peak flows in the field using a portable computer [abs.]: U.S. Geological Survey National Computer Technology Meeting, programs and abstracts, Rancho Mirage, Calif., May 19-24, 1996: U.S. Geological Survey Open-File Report 96-204. (Also available at http://pubs.usgs.gov/of/1996/0204/.)

Dalrymple, Tate, and Benson, M.A., 1967, Measurement of peak discharge by the slope-area method: U.S. Geological Survey Techniques of Water-Resources Investigations Report, book 3, chap. A2, 12 p. (Also available at http://pubs.usgs.gov/twri/twri3-a2/.)

Fulford, J.M., 1994, User's guide to SAC, a computer program for computing discharge by slope-area method: U.S. Geological Survey Open-File Report 94-360, 31 p. (Also available at http://water.usgs.gov/software/SAC/code/doc/ sacman.pdf.)

Hortness, J.E., 2004, SAM 2.1-A computer program for plotting and formatting surveying data for estimating peak discharges by the slope-area method: U.S. Geological Survey Fact Sheet 2004-3028, 4 p., accessed July 23, 2012, at http:// pubs.er.usgs.gov/publication/fs20043028.
Table 2. Supported point identifier and high-water-mark quality codes.

\begin{tabular}{|c|c|}
\hline \multicolumn{2}{|r|}{ Point identifiers } \\
\hline Code & Description \\
\hline BM & Benchmark \\
\hline RM & Reference mark \\
\hline HUB & Surveying or turning point \\
\hline LH & Left-bank high-water mark \\
\hline RH & Right-bank high-water mark \\
\hline GH & Stream gage \\
\hline $\mathrm{X}[1]$ & $\begin{array}{l}\text { Cross-section point. [1] indicates the cross-section } \\
\text { number (for example, "X1," "X2," and so forth) }\end{array}$ \\
\hline \multicolumn{2}{|r|}{ High water mark quality codes } \\
\hline Code & Description \\
\hline $\mathrm{E}$ & Excellent \\
\hline G & Good \\
\hline $\mathrm{F}$ & Fair \\
\hline$P$ & Poor \\
\hline
\end{tabular}

\section{For more information about the SAC GUI, please contact H2osoft@usgs.gov.}

